\section{Herpes simplex virus infection in the media of donor corneas during organ culture: frequency and consequences}

ULRIKE SENGLER, THOMAS REINHARD, ORTWIN ADAMS, CATHARINA KREMPE, RAINER SUNDMACHER

\author{
U. Sengler \\ T. Reinhard \\ R. Sundmacher \\ Eye Hospital \\ Heinrich Heine University \\ Duesseldorf \\ Germany \\ O. Adams \\ C. Krempe \\ Institute of Medical \\ Microbiology and Virology \\ Heinrich Heine University \\ Duesseldorf, Germany
}

Ulrike Sengler

Eye Hospital

Heinrich Heine University

Moorenstrasse 5

D-40225 Duesseldorf, Germany

Tel: +49 2118117320

Fax: +492118116241

e-mail:

sengler@uni-duesseldorf.de

Received: 6 December 2000 Accepted in revised form: 6 April 2001

\section{Abstract}

Background and purpose According to polymerase chain reaction (PCR) studies $2-38 \%$ of organ culture donor corneas may contain herpes simplex virus (HSV) DNA, but there are only 6 reported instances of proven virus replication in a corneoscleral disc. Moreover there are only 6 patients reported in whom primary graft failure and extensive post-operative epithelial defects were probably caused by a herpetic infection of the corneal graft. Recently we observed virus replication in a donor cornea with subsequent complete endothelial necrosis in our cornea bank. The aim of this study was to investigate the possible correlation between herpetic donor cornea infection and endothelial necrosis in organ culture.

Methods To evaluate the frequency of HSV as a reason for endothelial necrosis in organ culture we tested the media of 199 donor corneas discarded due to an altered endothelium in the years 1997 to 1999 by PCR for HSV. As a negative control group we screened the media of 117 transplanted corneas using PCR.

Results In the control group we had only negative PCR results, in contrast to the corneas with severe or complete endothelial necrosis where HSV DNA was detected in 12 media of the corneas of 9 donors. Virus could be cultivated out of 7 media.

Conclusions (1) HSV replication is a common cause of severe endothelial necrosis in organ culture corneas. (2) Replication of the virus during organ culture comes close to a virus cultivation using the corneoscleral disc as a cell culture. (3) We consider the danger of transplanting active $\mathrm{HSV}$ to be very small if critical assessment of the graft prior to surgery is carried out.

Key words Donor corneas, Endothelial necrosis, Herpes simplex virus, Organ culture
Up to $70 \%$ of 15 - to 25 -year-olds are seropositive for herpes simplex virus (HSV) type 1 and this proportion rises to $95-97 \%$ by 60 years of age. ${ }^{1,2}$ The estimated prevalence of a HSV infection is approximately 150 per 100000 population. ${ }^{3}$

According to polymerase chain reaction (PCR) studies $2-38 \%$ of donor corneas stored in organ culture may contain the DNA of HSV. ${ }^{4-7}$ In contrast to this high percentage there are only 6 published cases of HSV replication being detected and documented in a corneoscleral disc. $^{4-11}$ In one case transmission of the disease by penetrating keratoplasty was postulated as the recipient suffered from primary graft failure and HSV DNA was detected in the medium of the fellow donor cornea which was discarded due to endothelial damage. ${ }^{4}$ In 2 more cases of primary graft failure HSV DNA was detected retrospectively by PCR in the explanted corneal buttons. Transmission of HSV was held responsible for the failure as the originally explanted corneal buttons were PCR-negative for HSV. ${ }^{12}$ Biswas et al. ${ }^{13}$ also published 2 cases in which early graft failure and persistent epithelial defects with following early graft failure were seen in combination with eye swabs positive for HSV in virus culture. In one recently published case the transmission of the herpetic disease by the transplantation was proven by identifying the same genotype in the donor- and recipient-derived HSV-1-strains. ${ }^{14}$ Furthermore, there are some reports on newly acquired herpetic ocular manifestations in connection with recently performed penetrating keratoplasty. ${ }^{15-18}$ The origin of the herpetic infection remains speculative in these few descriptions.

Last year we had a donor cornea in our eye bank that showed epithelial alterations like a typical herpetic dendrite in slit-lamp examination at the beginning of organ culture. After 1 week the initially healthy endothelium had changed to complete endothelial necrosis. HSV type 1 (HSV-1) was isolated in a virus 
culture out of a probe of the medium. ${ }^{10}$ The purpose of this study was to determine how often there is a correlation between HSV replication and endothelial necrosis of donor corneas in organ culture.

\section{Materials and methods}

To evaluate the frequency of HSV infection in donor corneas stored in organ culture we tested the media of 199 corneoscleral discs discarded due to endothelial necrosis and of 117 transplanted corneas. All donor corneas were stored in our eye bank in the years 1997-1999. The discarded corneas were frozen in their media at $-80^{\circ} \mathrm{C}$, as were the media of the transplanted corneas.

\section{Evaluation of endothelial necrosis}

The endothelium was examined in hypotonic balanced salt solution (BSS) by phase-contrast microscopy for swelling of the cell borders, endothelial morphology and cell density. ${ }^{19}$ We graded the discarded corneas into four groups according to the extent of endothelial alteration: group 1, only slight endothelial changes, necrosis of less than $10 \%$ of the endothelium, but centrally located or a cell count below 2000 cells $/ \mathrm{mm}^{2}(n=30)$; group 2, moderate endothelial changes, necrosis of between $10 \%$ and $50 \%$ of the endothelium ( $n=57)$; group 3 , severe endothelial changes, necrosis of more than $50 \%$ of the endothelium ( $n=91)$; group 4, complete endothelial necrosis, no viable endothelial cells $(n=21)$. The media of the 117 transplanted corneas with a healthy endothelium and a cell count above 2000 cells $/ \mathrm{mm}^{2}$ served as a control group.

\section{PCR analysis}

The frozen culture flasks containing the cell culture medium were thawed and $15 \mathrm{ml}$ of the medium was subjected to centrifugation at $2000 \mathrm{rpm}$ for $10 \mathrm{~min}$. The cell pellet was resuspended in $100 \mu \mathrm{l}$ lysis buffer containing Tween-20 and NP40, 0.5\% each, followed by digestion with proteinase $\mathrm{K}, 60 \mu \mathrm{g}$ per $\mathrm{ml}$. A $10 \mu \mathrm{l}$ aliquot was used for PCR using HSV primers as described by Cao et al. ${ }^{20}$ PCR reactions were performed under standard conditions for 40 cycles $\left(30 \mathrm{~s}\right.$ at $95^{\circ} \mathrm{C}, 30 \mathrm{~s}$ at $6{ }^{\circ} \mathrm{C}, 1 \mathrm{~min}$ at $72{ }^{\circ} \mathrm{C}$ ) using a Perkin Elmer model 9600 thermocycler. After electrophoresis on agarose gels, the PCR products were blotted onto a membrane and hybridised with a biotin-labelled probe followed by incubation with a streptavidin-linked alkaline phosphatase and NBT/BCIP. DNA extracted from cells infected with a laboratory strain of HSV served as a positive control. Aliquots from positive samples were tested with two further sets of primers as described by Cassinotti et al..$^{21}$ to distinguish between HSV-1 and HSV-2. The nested PCR as described by these authors was modified to a single-round PCR followed by a hybridisation with a biotinylated probe generated with the nested primer pair. The sensitivity was determined as 400 copies of a standard plasmid.

\section{Virus isolation}

One millilitre of cell-free medium of the organ culture was inoculated into cultures of HeLa cells and monitored daily for the appearance of a cytopathic effect (CPE) for a maximum of 14 days. In the cases with a positive result the CPE appeared within 2-5 days after inoculation. The positive results were confirmed by a standard immunofluorescence technique using mouse monoclonal antibodies against HSV-1 and HSV-2 (Syva Micro Trak, Behring Diagnostics).

\section{Results}

In the control group of 117 media from transplanted corneas with a healthy endothelium we had only negative PCR results. Among the discarded corneas a positive HSV PCR was seen in 12 media from the corneas of 9 donors $(6 \%)$. The positive results came only from corneas which had shown severe or complete endothelial necrosis (Table 1). In the group of the donor corneas with severe endothelial changes 3 of 91 (3\%) were positive for HSV by PCR, while in the group of corneoscleral discs with complete endothelial necrosis 9 of 21 (43\%) showed a positive result.

The second PCR to distinguish between HSV-1 and HSV-2 was performed with these 12 media. In 4 media no differentiation was possible, 6 media were positive for HSV-1 and 2 media (of the same patient) were positive for HSV-1 and HSV-2. These results are listed in Table 2.

Virus isolation was successful in 7 cases with positive PCR results and showed CPE within 5 days of culture. The results of the following typing into HSV-1 and HSV-2 were identical to that of the PCR typing in all cases. All 9 donors of the HSV-positive corneas had a history of a long-standing or severe illness often including a prolonged stay in hospital or even in the intensive care unit.

\section{Discussion}

In this study HSV was detected only in the media of discarded corneas with severe or complete endothelial necrosis. In the latter group HSV DNA could be found in almost half the media. We must conclude that in these cases HSV replication is responsible for endothelial

Table 1. Distribution of HSV-positive PCR results in the discarded corneas

\begin{tabular}{lcr}
\hline Grading of endothelial necrosis & PCR positive for HSV & $\%$ \\
\hline Group $1=$ slight & 0 of 30 & - \\
Group $2=$ moderate & 0 of 57 & - \\
Group $3=$ severe & 3 of 91 & 3 \\
Group 4 = complete & 9 of 21 & 43 \\
Total & 12 of 199 & 6 \\
\hline
\end{tabular}




\begin{tabular}{rlll}
\hline Cornea no. $^{a}$ & Grading of endothelial necrosis & PCR HSV-1/2 & Virus cultivation + differentiation \\
\hline 1 & Complete & No differentiation possible & Virus culture negative \\
2 & Complete & HSV-1 & Virus culture positive, HSV-1 \\
3 & Severe & No differentiation possible & Virus culture negative \\
4 & Severe & No differentiation possible & Virus culture negative \\
5 & Complete & HSV-1 & Virus culture positive, HSV-1 \\
6 & Severe & No differentiation possible & Virus culture negative \\
7 & Complete & HSV-1 & Virus culture positive, HSV-1 \\
8 & Complete & HSV-1 & Virus culture positive, HSV-1 \\
9 & Complete & HSV-1 & Virus culture positive, HSV-1 \\
10 & Complete & HSV-1 & Virus culture negative \\
11 & Complete & HSV-1 + HSV-2 & Virus culture positive, HSV-1 + HSV-2 \\
12 & Complete & HSV-1 + HSV-2 & Virus culture positive, HSV-1 + HSV-2 \\
\hline
\end{tabular}

${ }^{a}$ Corneas 4 and 5, 7 and 8 , and 11 and 12 are fellow corneas of the same donor.

necrosis resembling the cytopathic effects the virus causes in virus cultivation. We were not able to detect HSV DNA in the media of transplanted corneas or of discarded corneas with slight or moderate endothelial necrosis. This is in contrast to the findings of several previous publications. ${ }^{4-7}$ We cannot exclude the possibility that performing PCR with material directly taken from the corneoscleral discs - as in the studies by Cleator and Openshaw - is more sensitive than testing only the media for HSV DNA.,7 On the other hand, if there is active HSV in the donor cornea, replication of the virus in organ culture without the limiting influence of the immune system comes close to virus cultivation. This is supported by the fact that virus cultivation was successful in 7 of the PCR-positive cases within a few days due to effective replication of the virus. Therefore, one would not expect a lower sensitivity if only the media are tested.

The next question is how the virus gets into the organ culture. The answer must remain speculative. In our opinion, the most probable origin for HSV is as yet unrecognised HSV replication in the donor cornea at the time of death. This was the case in the donor cornea with a dendritic epithelial lesion and subsequent complete endothelial necrosis we observed in our cornea bank. Alternatively, latent virus within the trigeminal ganglion could just have reactivated before death, resulting in viral shedding in the corneal tissue. For both mechanisms the pre-mortem stress would serve as a trigger. All donors of corneas with a positive PCR result for HSV in our study had a history of a severe or longstanding disease and consequently probably a high amount of pre-mortem stress. The question of whether or not death may be an initiating factor of HSV was investigated by Cleator et al.," who consider viral shedding in the tear film or into the cornea by axonal transport at the time of death less likely. They also discuss possible contamination and the presence of HSV as a persistent infection or in a latent form within the corneal tissue at the time of death. Considering the age of the donors (range 36-77 years), a primary HSV infection seems improbable.
Finally, there have been some publications describing HSV DNA detection in asymptomatic corneas by $\mathrm{PCR},{ }^{22,23}$ and in donor corneas without history of herpetic disease in a high percentage of up to $38 \%{ }^{6}$ In these cases one must ask for the clinical meaning and consequences of a positive PCR result, especially given the fact that the estimated prevalence of herpetic eye disease is approximately 150 per $100000 .^{3}$ The hypothesis that in our study the corneas carried active and replicating virus is underlined by the fact that we were able to isolate and cultivate HSV. This was also used as a second method in typing HSV-1 and HSV-2. Interestingly, we observed replication of both HSV-1 and HSV-2 in one donor, which resulted in complete endothelial necrosis of both corneas.

How can we avoid the transplantation of donor corneas with HSV replication? Given our results, this possibility can almost be excluded if critical assessment of the endothelium is performed both throughout the culture period and shortly prior to transplantation. This point of view is in accordance with the literature: In their description of the connection between a herpetic infection of a donor cornea and the subsequent complete necrosis of the endothelium Tullo et al. ${ }^{8}$ emphasise that organ culture may serve as a 'screening method' in detecting infections. In the case of cold storage virus replication is also likely to occur, ${ }^{11}$ but as cold storage usually extends for only 1-7 days severe endothelial necrosis might not yet have occurred at the time of pretransplantation examination of the graft. Therefore, we consider cold storage to be less 'safe' in detecting cytopathic changes due to herpetic viral replication.

In 5 of the reported cases with suspected or proven HSV transmission by penetrating keratoplasty the time elapsed between the final examination of the graft and the transplantation is not mentioned. It might have been long enough that major endothelial changes were not yet visible at the time of graft assessment. ${ }^{4,12-14}$ In one of the cases published by Biswas et al. ${ }^{13}$ the graft was examined and assessed as suitable only 2 days before transplantation. One would have expected that major endothelial changes were already present after 16 days of organ culture if HSV was present at the time of the donor's death. The fellow cornea of this graft was 
discarded due to marked endothelial cell necrosis. Unfortunately, no viral examinations were performed. As HSV was cultured from eye swabs after graft failure, contamination of the transplanted donor cornea by the already infected and later discarded fellow cornea at the time of explantation or during the organ culture period may be a possible explanation for the late changes.

If endothelial necrosis due to a herpetic infection is detected in the cornea bank one should be aware that some risk of contamination of other grafts exists. Therefore, hygiene recommendations should be strictly adhered to. Furthermore, the fellow cornea of the affected donor should be examined very critically and not used for transplantation, as the explantation may have been performed with the same instruments. This is in accordance with the recommendations given by Biswas et al. ${ }^{13}$

In summary, we screened the media of organ culture donor corneas for HSV DNA by PCR and subsequent virus cultivation. We detected HSV DNA only in cases of severe or complete endothelial necrosis. We therefore agree with Tullo et al., ${ }^{8}$ who state the usefulness of organ culture in screening donor tissue for infective agents and their specific sequelae, which, in the case of herpetic infection, are a severe or even complete necrosis of the corneal cellular material.

The authors thank M. Thieme and A. Voges for their technical assistance.

\section{References}

1. Scott T. Epidemiology of herpetic infection. Am J Ophthalmol 1957;43:134-7.

2. Smith IW, Peutherer JF, MacCallum FO. The incidence of herpes virus hominis antibody in the population. J Hyg 1967;65:395-408.

3. Liesegang TJ, Melton LJ, Daly PJ, et al. Epidemiology of ocular herpes simplex: incidence in Rochester, Minn., 1950 through 1982. Arch Ophthalmol 1989;107:1155-9.

4. Cleator GM, Klapper PE, Dennett C, et al. Corneal donor infection by herpes simplex virus: herpes simplex virus DNA in donor corneas. Cornea 1994;13:294-304.

5. Morris DJ, Cleator GM, Klapper PE, et al. Detection of herpes simplex virus DNA in donor cornea culture medium by polymerase chain reaction. Br J Ophthalmol 1996;80:654-7.

6. Openshaw $\mathrm{H}$, McNeill JI, Lin $\mathrm{XH}$, et al. Herpes simplex virus DNA in normal corneas: persistence without viral shedding from ganglia. J Med Virol 1995;46:75-80.
7. Garweg JG, Boehnke M. Low rate shedding of HSV-1 DNA, but not of infectious virus, from human donor cornea into culture media. J Med Virol 1997;52:320-5.

8. Tullo AB, Marcyniuk B, Bonshek R, et al. Herpes virus in a corneal donor. Eye 1990;4:766-7.

9. Boehnke M, Garweg J, Germann D. Spontaneous endothelial necrosis in human donor cornea. International conference on herpetic eye disease 1992, New Orleans, LA, Abstract 23:4.

10. Sengler U, Spelsberg H, Reinhard T, et al. Herpes simplex virus (HSV) infection in a donor cornea. Br J Ophthalmol 1999;83:1405.

11. Neufeld MV, Steinemann TL, Merin LM, et al. Identification of a herpes simplex virus-induced dendrite in an Eye Bank donor cornea. Cornea 1999;18:489-92.

12. Cockerham GC, Krafft AE, McLean IW. Herpes simplex virus in primary graft failure. Arch Ophthalmol 1997;115:586-9.

13. Biswas S, Suresh P, Bonshek RE, Corbitt G, Tullo AB, Ridgway AEA. Graft failure in human donor corneas due to transmission of herpes simplex virus. Br J Ophthalmol 2000;84:701-5.

14. Remeijer L, Maertzdorf J, Doornenbal P, Verlans GM, Osterhaus AD. Herpes simplex virus 1 transmission through corneal transplantation. Lancet 2001;357:442.

15. Beyer CF, Byrd TJ, Hill JM, et al. HSV and persistent epithelial defects after penetrating keratoplasty. Am J Ophthalmol 1990;109:95-6.

16. Beyer CF, Hill JM, Byrd TJ, et al. Herpes simplex dendritic keratitis after keratoplasty [letter]. Am J Ophthalmol 1991;112:355-6.

17. Mannis MJ, Plotnik RD, Schwab IR, et al. Herpes simplex dendritic keratitis after keratoplasty. Am J Ophthalmol 1991;111:480-4.

18. Remeijer L, Doornenbal P, Geerards AJM, et al. Newly acquired herpes simplex virus keratitis after penetrating keratoplasty. Ophthalmology 1997;104:648-52.

19. Boehnke M. Spendergewebe für die Keratoplastik. Klin Monatsbl Augenheilkd 1991;198:562-71.

20. Cao M, Xiao X, Egbert B, et al. Rapid detection of cutaneous herpes simplex virus infection with polymerase chain reaction. J Invest Dermatol 1989;82:391-2.

21. Cassinotti P, Siegl G. A nested PCR assay for the simultaneous amplification of HSV-1, HSV-2 and HCMV genomes in patients with presumed herpetic CNS infections. J Virol Methods 1998;71:105-14.

22. Cantin EM, Chen J, McNeill J, et al. Detected of herpes simplex virus DNA sequences in corneal transplant recipients by polymerase chain reaction assays. Curr Eye Res 1991;10(Suppl):15-21.

23. Kaye SB, Lynas C, Patterson A, et al. Evidence for herpes simplex viral latency in the human cornea. Br J Ophthalmol 1991;75:195-200. 